\title{
El fénix sefardí. Sobre la existencia de un teatro judeo-ibérico en Italia (Proyecto E.S.THE.R.)*
}

\author{
Paola Bellomi** \\ Università degli Studi di Siena \\ ORCID ID: https://orcid.org/0000-0001-7390-4607
}

Si bien la producción poética y narrativa sefardí es bien conocida, en Italia falta un estudio de la producción dramática, un género amado y atendido por el público sefardí. La tendencia de los estudiosos es considerar los primeros siglos de la diáspora como un período escasamente prolífico desde un punto de vista artístico, precisamente debido a las migraciones que involucraron a comunidades enteras. Por el contrario, en el caso italiano, algunos investigadores han hablado de un «Siglo de oro de las letras sefardíes», un florecimiento cultural que se justifica con la estabilidad socioeconómica que las comunidades alcanzaron entre los siglos XVI y XVII, una condición necesaria para que también la literatura pudiera desarrollarse en un ambiente no tan conflictivo; por ejemplo, el texto inédito Entremés de un dotor (1616) es un fruto de ese contexto. Por estas razones, en las páginas que siguen nos proponemos estudiar la influencia de la cultura sefardí en el teatro italiano, en particular centrándonos en el área de la Toscana, una región que, desde la expulsión, se transformó en un «puerto seguro» para los hebreos ibéricos. El objetivo es detectar la posible contribución de los sefardíes en el drama italiano desde finales del Renacimiento y el Barroco hasta la época moderna. Para acercarnos a nuestro objetivo, primero presentaremos una serie de reflexiones sobre la definición de «identidad sefardí» y después comentaremos algunas experiencias teatrales surgidas en el ámbito judeo-español italiano.

Palabras Clave: Teatro del Siglo de Oro; Guido Bedarida; Yshac [Fernando] Cardoso; bagitto; Commedia dell'Arte; Leone de' Sommi.

The Sephardic Phoenix: Some Evidence of the Existence of an Italian Ladino Theatre (E.S.THE.R. Project).- While the Sephardic poetic and narrative production

* El presente artículo ha sido elaborado en el marco del Proyecto de Investigación SIR del Plan Nacional E.S.THE.R. «Enquiry on Sephardic THEatrical Representation», financiado por el MIUR [ref. núm. RBSI14IDE8]. Una versión abreviada del mismo fue presentada como comunicación en The Seventeenth World Congress of Jewish Studies, sección: Sephardic Studies, celebrado en la Universidad Hebrea de Jerusalén los días 6-10 de agosto de 2017.

** paola.bellomi@unisi.it

Copyright: (C) 2019 CSIC. Este es un artículo de acceso abierto distribuido bajo los términos de la licencia de uso y distribución Creative Commons Reconocimiento 4.0 Internacional (CC BY 4.0). 
is well known, in Italy there is a lack of a study of the dramatic production, a genre surely loved and attended by the Sephardic public. The scholars' trend is to consider the first centuries of the diaspora as a scarcely prolific period from an artistic point of view exactly because of the migrations that involved whole communities. On the contrary, in the Italian case the critics speak about a "Siglo de Oro de las Letras" of Sephardim who, between the 16th and the 17th century, were able to reach the necessary socio-economic stability to allow the flourishing of literature; the unpublished text Entremés de un dotor (1616) is an example of this crawling context. For these reasons, in this essay we propose to study the influence of Sephardic culture on Italian theater, in particular focusing on the area of Tuscany, a region that, since the expulsion, became a "safe harbor" for Jewish people. The objective is to detect the possible contribution of the Sephardim in the Italian drama of the late Renaissance and the Baroque to the modern era. To get closer to our objective, we will first present a series of reflections on the definition of «Sephardic identity» and, secondarily, we will comment on some theatrical texts that emerged in the Italian Judeo-Spanish area.

KeYwords: Spanish Golden Age theatre; Guido Bedarida; Yshac [Fernando] Cardoso; Bagitto; Commedia dell'Arte; Leone de' Sommi.

Tres días antes de su muerte, Lope de Vega había querido asistir a la defensa de la tesis de medicina y filosofía del Dr. Fernando (Yshac) Cardoso; justo poco después, el Fénix de los Ingenios se sintió mal, quizá por haber comido «unos huevos duros y unos fideos guisados», como se sugiere en la edición de 1779 de la Colección de obras sueltas [...] de Lope de Vega ${ }^{1}$. Cardoso, catedrático de la Universidad de Valladolid y médico de cámara de Felipe $\mathrm{IV}^{2}$, quiso homenajear al dramaturgo con un panegírico titulado Oración fúnebre en la muerte de Lope de Vega en el cual Cardoso subrayaba la importancia de la extensa producción teatral de Lope y comentaba:

${ }^{1}$ Lope DE Vega, Colección de las obras sueltas, assi en prosa, como en verso (Madrid: en la imprenta de Don Antonio de Sancha, 1779) vol. 20, pág. 38; véanse también Yosef Hayim Yerushalmi, Dalla corte al ghetto: la vita, le opere, le peregrinazioni del marrano Cardoso nell'Europa del Seicento (Milano: Garzanti, 1991) págs. 149-153 (al no haber tenido acceso a la edición española del texto, empleamos la edición italiana) y los estudios de Yosef Kaplan sobre la figura de Cardoso, en particular su edición en hebreo a Isaac CARDoso, Las excelencias de los hebreos (Jerusalem: The Bialik Institute-Dorot Library, 1971).

2 Ruth Fine, Michèle Guillemont y Juan Diego Vila, (eds.), Lo converso: orden imaginario y realidad en la cultura española: siglos 14.-17 (Madrid Frankfurt am Main: Iberoamericana, 2013) pág. 57. 
Fueron sus Comedias un exemplar de las costumbres, un espejo de la vida, un desengaño del tiempo, y una persuasión de la virtud. [...] Ver en el theatro las acciones del furioso, del inobediente, del avaro, del lascivo, ¿qué es otra cosa sino documentos exemplares al retiro destas culpas, y una viva representación de los fines miserables que conducen? porque cautelosos nos desviemos del vicio, que al passo que deleyta, lástima. Ver premiada la fortaleza, vencedora la templanza, gloriosa la castidad, y subida la prudencia, estimulos son bizarros que nos alientan a obras virtuosas; que mas nos mueve lo representado, que lo escrito ${ }^{3}$.

La opinión de Cardoso sobre el teatro como herramienta para el desarrollo del alma cambia totalmente cuando publica Las excelencias de los hebreos (Ámsterdam, 1679), una obra de carácter apologético en la cual el autor afirmaba:

Los libros de Comedias, y Novelas amorosas con sus dulces palabras, y ficciones poéticas son fuerte incitamiento de lascivia, y engañoso instrumento de perdición, perturbadores del ánimo, y violadores de la pureza piérdese el tiempo en ellos, y son maestros de vanidades, y vicios. Las comedias, y tragedias fueron inventadas por gentiles profanos, no por el santo pueblo de Ysrael a quien escogió el Señor para cantar sus alabanças Divinas, y no amores lascivos, y invenciones viciosas ${ }^{4}$.

Dos eventos biográficos determinan el cambio de visión sobre el teatro que Cardoso experimenta entre la muerte de Lope y la publicación de Las excelencias: el abandono de España por Italia (y, en concreto, por la ciudad de Verona, donde reside durante treinta años, hasta su muerte, en 1683); y la vuelta al judaísmo (había nacido en ca. 1603 en una familia de cristianos nuevos portugueses) ${ }^{5}$. La posición contraria al mundo de las Comedias que Cardoso adopta ejemplifica la relación conflictiva entre el arte escénico y la cultura judía. Como es bien sabido, en el hebraísmo durante muchos siglos había sido fuerte el veto al teatro, puesto que se asimilaban las representaciones escénicas a los espectáculos de entretenimiento de la sociedad romana, como las luchas de gla-

${ }^{3}$ Lope DE Vega, Colección de las obras sueltas, vol. 19, págs. 483-484.

4 Yshac CARdoso, Las excelencias [y calunias] de los hebreos (Amsterdam: en casa de David de Castro Tartas, 1679) pág. 75.

5 Yerushalmi, Dalla corte al ghetto y Fine, Guillemont y Vila, Lo converso. 
diadores en las arenas o las carreras de coches en los circos ${ }^{6}$. La desaprobación hacia el teatro que Cardoso expresa después de haber recuperado su identidad judía puede interpretarse como el deseo de mostrar, de manera patente, su sincera adhesión al judaísmo.

Sin embargo, en el mundo judío no todos compartían las posiciones más ortodoxas como las de Cardoso. Por ejemplo, es consabido que, en las comunidades sefardíes orientales, a partir del siglo XVIII y sobre todo en el siglo XIX, se desarrolla una producción teatral importante, escrita y representada, y tanto original como traducida de otras literaturas ${ }^{7}$. Además, como ha estudiado Harm den Boer ${ }^{8}$, en el seno de las comunidades judías asentadas en los Países Bajos pudo florecer una literatura sefardí. Figuras de relieve de este panorama cultural son, entre otros, los conocidos José Penso de la Vega y Miguel de Barrios ${ }^{9}$; es interesante notar que ambos intelectuales y dramaturgos pasaron una parte de sus vidas en Italia: Penso de la Vega (Espejo, Córdoba 1650-Ámsterdam 1692) vivió durante cinco años en Liorna, de 1675 a 1680, y allí fundó la Academia de los Sitibundos, con nombre idéntico a la homónima

6 Jefim SchirmanN, «Theatre and Music in the Italian Ghetti between the Sixteenth and Eighteenth Centuries» [en hebreo], Zion 29 (1964) págs. 59-111, y Raffaele EsPoSITO, La nascita del teatro ebraico: persone, testi e spettacoli dai primi esperimenti al 1948 (Torino: Accademia University Press, 2016) pág. 5.

7 Señalo en esta nota una serie de referencias básicas para acercarse al tema; para profundizar, recomiendo las informaciones bibliográficas que pueden verse en los siguientes artículos y libros de Elena RoMERo: «Teatro judeoespañol aljamiado: adiciones bibliográficas», Sefarad 28:2 (1968) págs. 403-408; «El teatro entre los sefardíes orientales», Sefarad 29:1 (1969) págs. 187-212; 29:2 (1969) págs. 429-440, 30:1 (1970) págs. 168-176 y 30:2 (1970) págs. 483-508; El teatro de los sefardies orientales (Madrid: CSIC, 1979. 3 vols.); Repertorio de noticias sobre el mundo teatral de los sefardies orientales (Madrid: CSIC, 1983); La creación literaria en lengua sefardí (Madrid: Mapfre, 1992); «Más teatro francés en judeoespañol», Sefarad 52:2 (1992) págs. 527-540, y «Nueva bibliografía de obras de teatro sefardíes», Sefarad 66:1 (2006) págs. 183-218. Véase también Paloma DíAz-MAs, Los sefardies: historia, lengua y cultura (Barcelona: Riopiedras, 1986).

${ }^{8}$ Harm DEN Boer, «El teatro entre los sefardíes de Amsterdam a fines del siglo XVII», Diálogos hispánicos de Amsterdam 8:3 (1989) págs. 679-690.

9 Harm DEN BoER, La literatura sefardi de Amsterdam (Alcalá de Henares: Instituto Internacional de Estudios Sefardíes y Andalusíes de la Universidad de Alcalá, 1995). 
academia holandesa ${ }^{10}$, mientras que Miguel de Barrios (Montilla, Córdoba 1635-Ámsterdam 1701) residió en la misma ciudad toscana, en casa de su tía Raquel Cohen de Soza, de 1660 a 1662 aproximadamente ${ }^{11}$. Según las palabras de Fernando Copello:

Si bien la experiencia italiana de Miguel de Barrios, en la misma ciudad de Liorna, quizá sea menos esencial (aunque es la que determina su regreso al judaísmo), no podemos dejar de destacar que los dos grandes escritores hispánicos de Ámsterdam [Penso de la Vega y Barrios] pasan por una estancia-aprendizaje italiana inmersos en la misma comunidad sefardí del Mediterráneo ${ }^{12}$.

Italia es un país importante para la diáspora sefardí, aunque a menudo se ha visto más como una etapa de tránsito hacia otros destinos (como los territorios del Imperio Otomano y la Tierra de Israel) que un país de acogida, por lo menos en una primera fase, que María Felisa Bermejo Calleja delimita cronológicamente entre el edicto de expulsión y $1570{ }^{13}$. La segunda fase (1570-1700) «se caracteriza por la llegada de muchas y potentes comunidades - llamadas también naciones - de sefarditas, españoles y portugueses, que venían de las costas del Mediterráneo Oriental» ${ }^{14}$. En efecto, si hasta este momento habían sido las ciudades de Roma y Nápoles los centros más importantes del sefardismo en Italia,

10 Valentina NiDER, «José Penso e l'accademia sefardita «de los Sitibundos» di Livorno nella diffusione di un genere oratorio tra Italia e Spagna: traduzione e imitazione nelle Ideas Posibles (1692)», Studi Secenteschi 51 (2010) págs. 153-197.

11 Fernando Copello, «Hibridismo y variedad en una novela corta de Joseph Penso de la Vega y Miguel de Barrios: Fineza de la amistad y triunfo de la inocencia (¿Amsterdam?, 1683)», Mélanges de la Casa de Velázquez. Nouvelle série 43:2 (2013) págs. 119-137: 122.

12 Copello, «Hibridismo y variedad» págs. 123-124.

13 M. ${ }^{a}$ Felisa Bermejo Calleja, «La diáspora sefardí en Italia a raíz de la expulsión de España en 1492 de los judíos», Artifara 1 (2002), págs. [sin número], <http://www. ojs.unito.it/index.php/artifara/article/view/2367/2172>.

14 Bermejo Calleja, «La diáspora sefardí en Italia». El estudio de las redes comerciales que existían entre las comunidades sefardíes - y, más en general, judías - italianas y las de los países mediterráneos permite apreciar la profundidad y solidez de las relaciones, también culturales, entre los sefardíes de la diáspora. Véase Francesca TriveLLATO, Il commercio interculturale: la diaspora sefardita, Livorno e i traffici globali in età moderna (Roma: Viella, 2016). 
la situación cambia a partir del fuerte impulso comercial que Venecia, Liorna y Ancona logran dar en el Mediterráneo y, en particular, en los territorios del Imperio Otomano. Las plazas comerciales como la de Venecia llegan a ocupar una posición preeminente para los sefardíes levantinos, que en sus puertos encuentran nuevas posibilidades, hasta tener:

Un peso político, económico y cultural de primer orden en las ciudades en las que viven; y será en este período en el que las lenguas castellanas y portugueses se utilizarán entre los sefarditas en ciudades italianas y para la redacción de libros que verán la luz precisamente en este período. [...] Por último, hay que señalar que tras las fluctuaciones y la inestabilidad que representa el siglo XVI para los sefarditas en Italia, en cambio el XVII va a representar el siglo de oro de los sefarditas especialmente en Venecia y en Liorna ${ }^{15}$.

Italia es un caso peculiar dentro del contexto de la cultura judía puesto que es el primer país occidental que puede reclamar un teatro declaradamente hebreo, escrito en el idioma sagrado por autores judíos y dirigido a un público hebreo: me refiero a la experiencia promovida por Leone de' Sommi en la Mantua de los Gonzaga, ciudad que gozó también de una compañía dramática judía estable. Sommi escribió cerca de catorce comedias en italiano y al menos una en hebreo (Zakhut Bedihutà deKiddushim, es decir La comedia del matrimonio, ca. 1550), además del importantísimo tratado sobre el arte escénico titulado Quattro Dialoghi in Materia di Rappresentazioni Sceniche (Cuatro diálogos en materia de representaciones escénicas), escrito entre 1556 y $1589^{16}$.

Leone de' Sommi no fue un únicum. Si volvemos a centrar la atención en la cultura sefardí, nos encontramos con el ejemplo del rabino Moisés Zacuto ben Mordecai [sic], nacido en Ámsterdam en 1625 en el seno de una familia conversa portuguesa, amigo de Miguel de Barrios y compa-

15 Bermejo Calleja, «La diáspora sefardí en Italia».

16 Véanse Leone DE' Sommi, Quattro dialoghi in materia di rappresentazioni sceniche (Milano: Il polifilo, 1968); Jacobo Kaufmann, «Leone de Sommi, hombre de teatro cabal», Raices: revista judía de cultura 87 (2011) págs. 68-74, y Giorgio PAVESI, Leone de' Sommi hebreo e il teatro della modernità (Asola: Gilgamesh edizioni, 2015). 
ñero de estudios de Baruch Spinoza ${ }^{17}$. En 1645 se trasladó a Venecia, donde quedó hasta 1673, cuando fue llamado a ejercer como rabino de Mantua, donde quedó hasta su muerte en 1697. Zacuto, además de una importante producción cabalística, es también autor de por lo menos tres obras teatrales escritas en hebreo: La fundación eterna (1642), El infierno imaginado y El paraíso imaginado, estas dos inspiradas en la Divina Commedia de Dante ${ }^{18}$.

Si nos mudamos a Venecia, otro ejemplo de teatro relacionado con la cultura judía sería la tragedia Ester publicada por Leone Modena en 1619 , re-escritura de una versión anterior firmada por el converso Salomón Usque. Según los escasos datos que nos han llegado sobre la Ester de Usque, podemos deducir que este drama se puso en escena por primera vez en el gueto $c a$. 1531 y que volvió a ser representado, en ese mismo perímetro urbano, en dos ocasiones, es decir en 1559 y $1592^{19}$.

Estas son algunas de las huellas dejadas por escritores de origen converso o sefardí en Italia. Pero no son las únicas. El proyecto E.S.THE.R. «Enquiry on Sephardic THEatrical Representation» se pro-

17 Véase Joseph Jacobs y Meyer Kayserling, «Zacuto, Moses ben Mordecai», en Jewish Encyclopedia, <http://www.jewishencyclopedia.com/articles/15144-zacuto-moses-ben-mordecai>.

18 Henri V. Besso, «Dramatic Literature of the Spanish and Portuguese Jews of Amsterdam in the XVIIth and XVIIIth centuries (III-IV)», Bulletin Hispanique 40:2 (1938) págs. 158-175; Andrea Y. LATTES, «L'opera letteraria di Rabbi Moshè Zacuto», La Rassegna Mensile di Israel 63:2 (1997) págs. 1-26, y EsPosito, La nascita del teatro ebraico, págs. 21-26.

19 Véanse Jordi Canals, «Una canción inédita de Salomón Usque», Sefarad 64:1 (2004) págs. 3-25, y «Vida y obra de Salomón Usque», en Francesco Petrarca. De los sonetos, canciones, mandriales y sextinas del gran poeta y orador Francisco Petrarca; traduzidos de toscano por Salomón Usque (Venecia, 1567) (Trento: Università degli studi di Trento, 2009) págs. 27-52; Andrea ZINATO, «Medicina e diaspora sefardita. Jacob Uziel, medico e poeta, nella Venezia del Seicento», en Malattia e scrittura. Il corpo malato. Saperi medici, malattie e cure nelle letterature iberiche, ed. Silvia MoNTI (Verona: Cierre, 2012) págs. 185-224 y «Poesía y cultura literaria en el Ghetto de Venecia (s. XVII): Jacob Uziel, Sara Copio Sullam, Ansaldo Cebà, Gabriele Zinani», en Trayectorias literarias hispánicas: redes, irradiaciones y confluencias, eds. Maria Rosso, Felice Gambin, Giuliana CAlabrese y Simone Cattaneo (Roma: AISPI, 2018) págs. 289-309; Gabriella Zavan, Gli ebrei, i marrani e la figura di Salomón Usque (Treviso: Santi Quaranta, 2004), y Riccardo Calimani, Storia del ghetto di Venezia: 1516-2016 (Milano: Mondadori, 2016). 
pone el estudio de los pocos y esparcidos datos que han quedado sobre el mundo teatral relacionado con las comunidades judeo-españolas presentes en los territorios de la península itálica.

Como ha demostrado en sus estudios Pier Cesare Ioly Zorattini, la figura de la reina Ester y, por consiguiente, la fiesta de Purim han cobrado un significado especial en la historia de la diáspora sefardí, ya que:

Purim infine con la sua carica liberatoria fu forse la festa della tradizione ebraica più amata dai Marrani in quanto essi identificavano la propria condizione di dissimulazione/simulazione, cioè il loro destino di Criptogiudei, con quello di Ester, costretta inizialmente a celare la propria identità ad Assuero per poter salvare il suo popolo dalle trame di Aman. [...] Alla luce delle loro drammatiche vicende la storia narrata nel libro di Ester acquistava per i Giudaizzanti iberici un valore paradigmatico, diventa un pegno e un simbolo di salvezza, una festa da celebrare in qualsiasi condizione ${ }^{20}$.

El término «representation» que cierra el acrónimo de E.S.THE.R. se puede interpretar de dos formas: por un lado, hace referencia al arte escénico, al teatro como expresión creativa de la cultura judeo-española insertada en el contexto italiano; por otro lado, alude a los modos que estas comunidades (individual o colectivamente) adoptaron para representarse a sí mismas en un entorno cuya mayoría era cristiana, con lo cual ajena y potencialmente enemiga (como demuestran las repetidas y continuas persecuciones en el país y en momentos y situaciones políticoeconómicas muy desiguales en el tiempo).

El interrogante en el que se basa el proyecto es, in primis, si existió un teatro sefardí en el contexto italiano; al que sigue otra pregunta, relacionada con el concepto de identidad: ¿qué es lo que define el carácter o la esencia sefardí? Nuestra hipótesis se justifica y se apoya en los estudios de Elena Romero y los equipos de trabajo de los proyectos del CSIC sobre el teatro de los sefardíes orientales.

Resumiendo las palabras de Romero, Italia fue una de las metas de los sefardíes occidentales, aunque con el tiempo la asimilación hizo que

20 Pier Cesare Ioly Zorattini, (ed.), L'identità dissimulata. Giudaizzanti iberici nell'Europa cristiana dell'età moderna (Firenze: Olschki, 2000) págs. 5-14: 11. 
estas comunidades perdieran un rasgo determinante: la lengua de origen $^{21}$. Según Romero, es correcto definir como sefardíes aquellas

obras producidas por los sefardíes [asentados en los Balcanes] en esa lengua a la que me acabo de referir, el judeoespañol, el cual, a partir de las diversas modalidades de las lenguas hispanas de finales del siglo XV y con las normales evoluciones y cambios de una lengua viva, les ha servido de vehículo de comunicación oral y escrita durante más de cuatro siglos 22 .

Hemos intentado reflexionar sobre la posibilidad de emplear los criterios identificados por Romero para el estudio de la producción dramática sefardí fuera del perímetro geo-político del Imperio Otomano. En principio, la definición propuesta por la investigadora parecería excluir del ámbito sefardí la producción de autores judíos de habla hispana, como el ya citado Miguel de Barrios, por no mostrar caracteres distintivos con respecto a la producción literaria española de ese momento, es decir, la del Siglo de Oro ${ }^{23}$. Al mismo tiempo, no se deberían considerar como sefardíes las obras de autores hebreos de origen ibérico que, asentados en países como Italia, se expresen en el idioma local y ya no en judeo-español, es decir que hayan adoptado o hayan aprendido y se expresen en uno de los dialectos hebreos nacionales ${ }^{24}$.

Una sentencia rabínica de 1562 parecería corroborar esta posición. Nos estamos refiriendo al «problema» identitario que estaba interesando, por entonces, la comunidad de Safed, es decir cómo establecer la pertenencia a un grupo judío u otro. En concreto, al rabino Moses de Trani (nacido en 1505 en Salónica, aunque de familia pullés) se le presenta un caso relacionado con los sefardíes aragoneses. Para decidir a qué congregación pertenecen los nuevos judíos que llegan a Safed, el rabino llega a la siguiente conclusión: si el padre y el hijo habían nacido en Italia y el abuelo en Portugal, Castilla o Aragón, la comunidad de aco-

21 Elena Romero, «Historia y creación literaria de los sefardíes: una visión de conjunto», en El camino de la lengua castellana y su expansión en el Mediterráneo: las rutas de Sefarad, ed. Elena Romero (Estella: Calle Mayor, 2008) págs. 61-99: 64-65.

22 Romero, «Historia y creación literaria de los sefardíes», pág. 73.

23 Romero, «Historia y creación literaria de los sefardíes», pág. 72.

24 Romero, «Historia y creación literaria de los sefardíes», pág. 73. 
gida tenía que ser la italiana; en cambio, si el hijo había nacido en Italia, mientras que el padre y el abuelo no, la comunidad de pertenencia tenía que ser la de la «lengua» hablada por el padre. Con lo cual, si un niño había nacido en Italia de padre aragonés, era un miembro de esta misma comunidad; en el caso de que tanto el padre como el hijo hubieran nacido en Italia, pertenecerían a la comunidad italiana ${ }^{25}$.

A raíz de las reacciones negativas de los miembros de la comunidad aragonesa (que rechazaban el principio de que alguien perteneciera a una comunidad según el país de nacimiento), Trani vuelve sobre la cuestión y determina que la filiación a una congregación tiene que ver con el idioma en el que esa persona se reconoce como hablante:

Whoever comes from Italy, even though he, or his father, was born there, and his father['s family] came from the kingdom of Aragon, socalled on account of the Aragonese language, he should belong to the Aragonese congregation according to the custom that everyone should belong to the congregation of those people [who speak] his language and not another one ${ }^{26}$.

Trani está estableciendo, de facto, una relación de dependencia entre lengua y cultura de una comunidad. David Bunis, en una reciente publicación sobre la posibilidad de considerar el «carácter judaico» (Jewishness) como un criterio de clasificación de las «lenguas de los sefardíes», afirma:

With the expulsions of the Jews from Iberia at the end of the fifteenth century, their sacred tongue as well as their vernacular language varieties were transported to entirely new linguistic and sociocultural surroundings. [...] Taking advantage of the opportunity to simply continue using their own language - on the model of the other ethnic groups they met in the empire, all of whom continued to speak and write their own languages among themselves following the conquest of the region by the Turks - the Ottoman Jews as a group did not use Turkish as their internal group language until the twentieth century, with the promulgation of the Turkish Republic. In the sixteenth century, the more veteran Jewish groups of the empire - including the Romaniotes, and the Italian and

25 En Matthias B. LehmanN, «Introduction: Sephardi Identities», Jewish Social Studies: History, Culture, Society 15:1 (2008) págs. 1-9: 1-2.

26 En LehmanN, «Introduction: Sephardi Identities», pág. 2. 
Ashkenazi Jews - gradually assimilated linguistically to the now numerically predominant Sephardim, quickly making the emergent Ottoman Judezmo the language of practically all Ottoman Jews ${ }^{27}$.

Las diferencias lingüísticas, religiosas y culturales permitieron no solo que los sefardíes se preservaran como comunidad hasta el siglo xx en los territorios orientales, sino que hasta llegaran a constituir el grupo mayoritario dentro de la minoría judía, asimilando a los grupos allí presentes (los italianos y los romaniotas).

Acerca de la reflexión sobre la definición de la identidad sefardí, el caso italiano presenta unos aspectos peculiares. La presencia española en Italia fue de larga e intensa duración e interesó grandes áreas del país; su herencia no se limitó a los ámbitos políticos y administrativos, sino también a los culturales y lingüísticos ${ }^{28}$. Italia fue al mismo tiempo tierra de expulsión y de acogida de los sefardíes y conversos que, en algunos casos, al encontrarse en los territorios administrados por los españoles (como Sicilia o el Reino de Nápoles) durante la emanación de los edictos o las persecuciones inquisitoriales, pudieron encontrar reparo en los dominios confinantes, cuyos gobernantes se demostraron más tolerantes con los expulsados judíos.

Si nos fijamos en el ejemplo del Gran Ducado de Toscana, la familia Médici demostró, también a través de una legislación favorable, una apertura notable hacia los exiliados sefardíes y los conversos ibéricos; con la promulgación de las leyes «livornine» (1591 y 1593) se garantizó protección a los inmigrantes judíos de cualquiera «nazione», fueran ellos «moros», «turcos», «levantinos», «ponentinos», «españoles» o «portugueses» (así se les denomina en el edicto «la Liornina» de 1593). Desde el punto de vista lingüístico, como ha señalado David Bunis, los judíos

27 David Bunis, «Speakers' «Jewishness» as a Criterion for the Classification of Languages: The Case of the Languages of the Sephardim», Hispania Judaica Bulletin 12 (2016) págs. 1-58: 20-21.

${ }_{28} \mathrm{M}^{\text {a }}$ Teresa CACHO, «Italia mira a España. Manuscritos históricos hispánicos de los siglos XVI y XVII en bibliotecas italianas», e-Spania 24 (2016), <http://e-spania. revues.org/25637>; M. ${ }^{a}$ de las Nieves MuÑIz MuÑIz, L'immagine riflessa: percezione nazionale e trame intertestuali fra Italia e Spagna (da Petrarca a Montale, da Garcilaso a Guillén) (Firenze: Franco Cesati, 2012), y Maria Grazia Profeti, Importare letteratura: Italia e Spagna (Alessandria: Edizioni dell’Orso, 1993). 
de origen ibérico que se asentaron en Livorno (o Liorna) en el siglo XVII hablaban por lo menos tres variantes derivadas de los antiguos idiomas de Sefarad:

a) al ser los descendientes de familias conversas, estos inmigrantes usan el español o el portugués al igual que los cristianos sus contemporáneos;

b) los inmigrantes «levantinos», por tanto judíos provenientes del Imperio Otomano y que nunca tuvieron que convertirse al cristianismo, llegan a Liorna hablando una evolución de los idiomas de la diáspora sefardí;

c) los judíos que llegan del Norte de África hablan haquitía, evolución de las hablas ibéricas pre-expulsión que, con el paso del tiempo y las influencias del nuevo entorno lingüístico, se desarrollan de manera independiente del castellano o del portugués peninsulares 29 .

Al final, concluye Bunis ${ }^{30}$, las tres variantes desaparecieron $\mathrm{y}$, en parte, confluyeron en el bagitto, es decir, el habla de los judíos de Liorna que ha sobrevivido hasta hoy en día.

Entre los testimonios literarios que reflejan esta realidad heterogénea y cambiante se puede nombrar un número (lamentablemente reducido) de obras teatrales que siguen planteándonos la cuestión sobre cómo se define la identidad, en particular por lo que se refiere a los judíos de origen ibérico asentados en Italia.

El primer texto de este corpus es una pieza breve titulada Entremés de un dotor $i$ lo que izieron [n] sus criados, identificado, estudiado y transcrito por Valentina Nider $^{31}$. Se trata de un canovaccio, anterior a 1616, que se ha conservado en un cuadernillo manuscrito como parte de la documentación judicial de un proceso de la Inquisición que se celebró

${ }^{29}$ David M. BunIS, «Jewish Ibero-Romance in Livorno», Italia: studi e ricerche sulla cultura e sulla letteratura degli ebrei d'Italia XVIII (2008) págs. 7-64: 10-11.

30 BunIs, «Jewish Ibero-Romance in Livorno», pág. 64.

31 Valentina NIDER, «El Entremés de un dotor y lo que iziero[n] sus criados, inédito, en los papeles de la Inquisición de Pisa: ¿un scenario?», en Por tal variedad tiene belleza. Omaggio a Maria Grazia Profeti, eds. Antonella Gallo y Katerina Vaiopoulos (Firenze: Alinea, 2012) págs. 323-336. 
el 20 de enero de $1616^{32}$. El proceso se había producido por la acusación de blasfemia de un texto puesto en escena en Pisa durante el Carnaval; los acusados fueron unos jóvenes portugueses, católicos y judíos. La obra acusada era el Entremés de la Infanta Palancona, cuyo texto se halla en el mismo cuadernillo en el que se encuentra el otro entremés, anónimo y nunca representado: Un dotor i lo que izieron[n] sus criados; el argumento del canovaccio que aquí nos interesa es el siguiente: un médico tiene que dejar su casa porque le han pedido que se dirija rápidamente a Constantinopla. Durante su ausencia, sus dos criados sacan provecho de la fama del médico para ganar dinero; uno de ellos se viste de cirujano y, con la ayuda del otro, recibe a los pacientes dándoles unos tratamientos completamente equivocados, que causan la muerte de los enfermos. En el desenlace, el médico vuelve de Constantinopla y tiene que defenderse de la acusación de homicidio; se salva gracias a algunos testigos, que ponen al descubierto el engaño de los dos criados.

Como ha puesto en evidencia Valentina Nider en su estudio sobre este entremés, el argumento de la obra es una adaptación del texto atribuido a Lope de Rueda Paso primero del médico simple y Coladilla paje, y el doctor Valverde y del Entremés del doctor simple de Lope de Vega ${ }^{33}$. Desde el punto de vista lingüístico, el anónimo entremés italiano es un «texto que presenta numerosos lusitanismos y alguna interferencia con el italiano y que parece haber sido confeccionado en Italia por un escribiente portugués» ${ }^{34}$. Gracias a las declaraciones conservadas en la documentación judicial, sabemos que un tal Iacob, hijo de Isaac Israele, testimonió que había sido un judío que vivía en Pisa a entregarles el cuadernillo a los acusados ${ }^{35}$. Este dato biográfico, junto con el idioma empleado y, quizá, la referencia que se encuentra en el canovaccio a la ciudad de Constantinopla (uno de los mayores centros sefardíes), permiten relacionar el entremés con un autor converso, cuando no sefardí (no hay informaciones que corroboren una hipótesis en lugar de la otra). El idioma empleado en este texto nos restituye una heterogeneidad que no encaja completamente en ninguno de los perfiles propuestos por Bunis

\footnotetext{
32 NiDER, «El Entremés de un dotor y lo que iziero[n] sus criados», pág. 331.

33 NiDER, «El Entremés de un dotor y lo que iziero[n] sus criados», pág. 325.

34 NiDER, «El Entremés de un dotor y lo que iziero[n] sus criados», págs. 324-325.

35 NidER, «El Entremés de un dotor y lo que iziero[n] sus criados», pág. 331.
} 
en su clasificación; y al mismo tiempo no permite delimitar dentro de un grupo unitario al anónimo autor (o autores) de la obra: ¿este dramaturgo se sentiría castellano o portugués o, quizá, ambos o hasta apátrida?

En el caso de este entremés, el idioma no sirve para dirimir la cuestión, ya que se trata de una muestra de una lengua inestable y en evolución, que no ha renunciado todavía a las huellas de Sefarad, pero que se está asentando en la nueva realidad, lingüística y cultural.

Desde la perspectiva del género literario, sin duda se trata de un teatro en línea con la producción española contemporánea, como demuestran los parecidos con las obras de Lope de Rueda y de Lope de Vega. Al mismo tiempo, se nota tanto en la forma como en la caracterización de los personajes el parentesco con la Commedia dell'Arte ${ }^{36}$, con lo cual se puede afirmar que, también desde el punto de vista del género, nos encontramos con una obra híbrida, entre el canon literario español y el italiano. Por último, es un texto que pertenece a los géneros «seculares» ${ }^{37}$; pero no se trata de una adaptación en términos de género, sino solamente de argumento: como en mucha literatura renacentista y barroca, se trata de un texto elaborado a partir de otras fuentes, adaptadas según el gusto de la época y el público a quien va dirigido y no se aleja del marco del género teatral en el que se origina, es decir el entremés.

Entonces, ¿podría una obra como este entremés ser considerada parte de un supuesto canon literario italo-sefardí? El mismo interrogante nos lo plantean otras dos piezas breves, identificadas y transcritas por JulioFélix Hernando Álvarez ${ }^{38}$. Se trata de dos loas conservadas manuscritas en el fondo Magliabechiano de la Biblioteca Nacional de Florencia, cuyos títulos completos son:

- Loa que representaron los hebreos en la ciudad y puerto de Livorne delante de sus Altezas serenísimas de el gran duque de Toscana y la gran duquesa, a su venida y reçevimiento en la fiesta

36 NIDER, «El Entremés de un dotor y lo que iziero[n] sus criados», pág. 324.

37 Romero, La creación literaria en lengua sefardí, págs. 22-23.

38 Julio-Félix Hernando Álvarez, «Teatro hispanojudío en Toscana durante el siglo XVII», en Los judaizantes en Europa y la literatura castellana del siglo de oro, ed. Fernando Díaz Esteban (Madrid: Letrúmero, 1994) págs. 192-214. 
que hicieron. Compuesta por Raphael, nieto de Montes, hebreo (título breve: Loa de Livorno, vv. 272).

- Loa para representar en la ciu[d]ad de Pisa, delante de sus Altezas serenísimas del gran Duque de Toscana y la gran duquesa, compuesta por Rafael Niento de Montes, hebreo (título breve: Loa de Pisa, vv. 324).

Ambas piezas son panegíricos en honor del gran duque de Toscana, Ferdinando II de Médici, y de su esposa, Vittoria della Rovere. Como se puede determinar de la lectura de estas dos obras, su fecha de composición es anterior al nacimiento del primer hijo de la pareja, Cosimo III (nacido en 1642), puesto que el autor les desea mucha descendencia a los cónyuges; además, de las continuas referencias al tálamo y a la unión de los esposos, se puede suponer que las loas se redactaron alrededor de la fecha del matrimonio de los grandes duques (1633). A pesar de que el autor declare su nombre y su credo religioso (Rafael, nieto de Montes o Nieto de Montes, hebreo), de esta figura no hay datos concretos; lo que en cambio se puede argüir del manuscrito es que se trata de un escribiente que maneja perfectamente el idioma castellano y, además, está insertado en la producción teatral española contemporánea a él, como demuestran las referencias a la mitología clásica y el empleo de metáforas que pertenecían al canon literario de la época (por ejemplo, se crean repetidos paralelismos con los dioses de la literatura profana, como Apolo); tampoco puede pasar desapercibida la semejanza con la Vida es sueño de Calderón (escrita en fecha contemporánea a las loas) cuando se lee:

La tierra, el agua y el ayre, / el fuego, actibo elemento, / el sol, la luna y estrellas, / signos, astros y luzeros, / Mercurio, Júpiter, Marte, / Saturno, esferas y Venus, / globos, abes, plantas, peçes, / los animales diversos, / las criaturas Racionales, / quanto ençierra el orbe inmenso / todos podrían ynbidiar / aqueste dichoso premio. / Fin (Loa de Livorno, vv. 261-272) ${ }^{39}$.

39 «SEGISMUNDO: [...] Yo en esas cortes bellas / de la inquieta república de estrellas / vi en el lugar primero / por rey de las estrellas el lucero. / Yo en esferas perfectas, / llamando el sol a cortes los planetas, / le vi que presidía / como mayor oráculo del día / Pues ¿cómo, si entre flores, entre estrellas, / piedras, signos, planetas, las más bellas / prefieren, tú has servido / la de menos beldad, habiendo sido / por más bella y hermosa, 
Estos dos breves textos dramáticos pueden insertarse dentro de la categoría a) propuesta por Bunis, es decir pueden haber sido escritas por un autor descendiente de conversos, con un dominio lingüístico del español igual que el de sus homólogos ibéricos. Por lo que atañe al género literario, es patente que las loas de Rafael nieto/Nieto de Montes se insertan en la tradición teatral española de su época; además, el uso de un lenguaje «estándar» puede encontrar justificación en los destinatarios de las obras, es decir la pareja de nobles toscanos, seguramente no nativos españoles. En este caso también, como en el comentado anteriormente, nos hallamos con una producción «secular», pero no diríamos que adoptada: el autor está insertado en una tradición literaria determinada, la que hoy denominamos del teatro español del Siglo de Oro, y sin embargo no renuncia a declarar su comunidad de pertenencia. En la Loa de Livorno afirma:

Hasta las humildes plantas / de nosotros, los hebreos, / si bien de tan alta suerte / por indignos nos tenemos / dámosle la bienbenida / con humilde ofreçimiento, / siendo afecto más felize / de amor el más berdadero (vv. 137-144).

Y en la Loa de Pisa se lee:

Apolo y musas del orbe, / que ynfluís graçia poética, / dadme luz para que diga / en brebe y suçinta esençia / yo, por todos los hebreos, / un pensamiento que pueda / mostrar que mi voluntad / se yguala con la que yntenta; / mas ya pareçe que Apolo / me lo promete (vv. 125-134).

¿Cómo considerar esta producción? ¿A qué canon pertenece? ¿Al de la literatura española del Siglo de Oro o al de la literatura italiana escrita en español? Y, dentro de la literatura judía, ¿sería correcto, como hace Hernando Álvarez, considerarla parte del teatro hispanojudío, a pesar de producirse fuera de los territorios ibéricos y de dirigirse a gobernantes «italianos»?

El último ejemplo que completa la reflexión que aquí estamos proponiendo nos acerca a nuestra contemporaneidad, al comienzo del siglo xx, cuando en Italia ya no existen los guetos, la emancipación ha

\footnotetext{
/ sol, lucero, diamante, estrella y rosa?»; Pedro CALderón de la BARCA, La vida es sueño (Madrid: Cátedra, 2015) vv. 1604-1617.
} 
contribuido a la integración de los judíos en la sociedad mayoritaria católica y, al mismo tiempo, ha terminado por coincidir con la etapa final de la asimilación lingüística de las comunidades que hasta ese momento, por la guetización, habían logrado preservar su identidad idiomática y cultural. En este contexto, Guido Bedarida, alias Eliezer ben David (1900-1962), se propone recuperar la identidad judía italiana justamente a partir del rescate de su propio entorno, es decir el de la comunidad de Liorna. Y decide centrarse en el teatro, visto como instrumento de desarrollo de su proyecto político-cultural ${ }^{40}$. Gracias a una élite intelectual a la que Bedarida también pertenece, en la segunda década del siglo xx se asiste en Italia a un resurgimiento del interés por las antiguas raíces judeo-españolas. En la operación de recuperación de este patrimonio artístico y social, Bedarida considera fundamental también la reivindicación del idioma característico de su comunidad, el bagitto.

La antología poética de Bedarida titulada Sonetti se abre con una composición en la cual el poeta se pregunta: «Serei Toscano ou serei Portuguéz? Judeo de judaria ou Christiao novo? Quem sabe? Agora basta Livornéz» ${ }^{41}$.

Y también en el primer texto teatral, que remonta a 1923, el Bedarida dramaturgo reivindica la relación con la mítica Sefarad. El protagonista del drama Io t'ho chiamato, Eliezer, es un «vero prototipo della condizione di un ebraismo assimilato, che non può tuttavia, nonostante tutto, rinnegare completamente se stesso ${ }^{42}$. La tragedia se desarrolla en la España tardo-medieval, cuando los reyes católicos emanan el edicto de expulsión y el protagonista, que se había alejado de su comunidad por amor a una goy, María, vuelve para ayudar a sus familiares delante del

${ }^{40}$ Umberto ForTis, Il ghetto in scena: teatro giudeo-italiano del Novecento (Roma: Carucci, 1989) pág. 65.

${ }^{41}$ La antología se publica en 1956, aunque la composición de los sonetos remonta a los años veinte. En Maria Carmela D’ANGELo, «Scrittori giudaico-livornesi, testimoni letterari di un'integrazione complessa», en Ebrei migranti: le voci della diaspora, eds. Raniero Speelman, Monica Jansen y Silvia Gaiga (Utrecht: Igitur Publishing, 2012) págs. 123-138: 128.

42 ForTis, Il ghetto in scena, pág. 66. 
peligro en el que están ${ }^{43}$. Bedarida, en este drama histórico, recupera la referencia al pasado mítico de la comunidad livornesa, pero, por lo menos en la primera versión del drama, no aprovecha los recursos lingüísticos del bagitto, quedando en el marco del teatro italiano judío tout court.

En cambio, en la comedia que publica en 1928, Un intermezzo di canzoni antiche, da ascoltarsi quan'è Purim, Bedarida da comienzo al texto con los siguientes versos:

El Dios bendito nos dexe ver / La Nacion de Amalek destruida, / Y su nombre santo engrandecido, / Y sea perpetuada esta alegria, / Y cada año, en este dia ${ }^{44}$

y enseguida comenta:

Questo entremés, o intermezzo all'uso di Spagna, è scritto in ebraicolivornese, il pittoresco bagito tuttora vivo, che al toscano mescola, o pure o corrotte, parole e frasi in ebraico e vecchie voci spagnole e portoghesi ${ }^{45}$.

La acción se desarrolla en el gueto de Liorna, durante la fiesta de Purim de 1750 «o lì intorno»; si nos fijamos en el dramatis personae, las referencias a los orígenes ibéricos son patentes: los personajes se identifican con nombres de ascendencia portuguesa o española (Sole Mendez, Luna Nugnez, Rosa Del Valle, Simhà Del Rio, Ishaàk levantino, Rodriguez, Navarra, De Paz, etc.). Sin embargo, el resurgimiento de esta tradición se revela aún más en la elección de algunas canciones que Bedarida recupera de varias antologías y que emplea para caracterizar a sus personajes. Así por ejemplo, Immanuel Navarra se dirige a la señora Sole Mendez cantando «sull'aria di Mihamonha [sic]»:

NAVARRA: [...] Es misvà de combidar / $\mathrm{Al}$ el que no tiene que comprar, / Ni vino ni gallinas ni basar, / Però que no quede sin alegrarse no. / (Le Mascare ripetono, e continuano la canzone, e strepitano $)^{46}$.

\footnotetext{
${ }^{43}$ ForTis, Il ghetto in scena, pág. 66.

44 Guido Bedarida [Eliezer BEN DAVID], «Un intermezzo di canzoni antiche», $L a$ Rassegna Mensile di Israel 23:6-7 (1928) págs. 271-302: 272.

45 Bedarida [Eliezer Ben David], «Un intermezzo di canzoni antiche», pág. 273.

46 Bedarida [Eliezer Ben DAvid], «Un intermezzo di canzoni antiche», pág. 279. Existe otra versión de este poema, recogido en forma oral en 1954 y cantado por el Gran 
Cuando Bedarida escribe y estrena sus obras, lo que queda de Sefarad en las comunidades italianas son unos restos en la memoria de los ancianos, en su léxico y en su sabiduría, que se expresa a través de refranes que remontan a siglos atrás. Fue necesario un proyecto cultural como el propuesto por el dramaturgo livornés para que los «nietos de Sefarad» recuperaran su nostalgia por la patria perdida y, por tanto, por sus costumbres y sentido de comunidad (que es la finalidad principal de la operación de Bedarida). Lo que se quiere preservar no es tanto un idioma (el bagitto o las más antiguas hablas judeo-españolas), sino la identidad que había logrado resistir, también gracias al empleo de esa lengua, hasta la época de la emancipación de los guetos. A este propósito, es interesante leer una reseña que, de este entremés, se hace en el periódico de la comunidad judía de Porto, ha-Lapíd; el anónimo articulista escribe:

Este entremês à espanhola, representado em Livorno no mês de março findo no dia da festa de Sushan Purim, é a primeira obra escrita em dialecto judeo-livornês. Ali se descreve a vida e costumes da pequena republica judaica (A naçâo hebrêa) de Livorno, originaria de Espanha e de Portugal, em 1700, durante uma noite de Purim. Os episodios e as scenas tratadas com vivacidade e firmeza, cançôes judaicas ineditas do seculo XVIII em italiano e em espanhol, os dizeres caracteristicos, verso robusto e sonoro, fazem deste entremês um documento historico e folclorico de primeira ordem, que nos revela um mundo tâo interessante e que ficou, comtudo, desconhecido até aquí, e um documento de uma arte muito original que será preciso marcar ${ }^{47}$.

Como han señalado Paloma Díaz-Mas y Harm den Boer, los sefardíes occidentales han vivido una situación intercultural y fronteriza continua. Afirman los dos estudiosos: "Anduvieron también bordeando fronteras lingüísticas, desde su lengua materna (el castellano o el portugués) a la lengua litúrgica de la religión que habían escogido como suya (el hebreo), pasando por las lenguas de comunicación o literarias de sus luga-

Rabino de Roma Elio Toaff (Liorna, 1915-Roma, 2015); véase Elena Romero, Los yantares de Purim. Coplas y poemas sefardies de contenido folclórico: estudio y edición de textos (Barcelona: Ed. Tirocinio, 2011), cap. 3, núm. 2.3, pág. 406.

47 AnÓNImo, «Novas publicações. Un intermezzo di canzoni antiche», ha-Lapid. Órgão da Comunidade Israelita do Porto 14 (1928) pág. 6. 
res de asentamiento» ${ }^{48}$. Contrariamente a los sefardíes orientales, los hebreos de España y los conversos que encontraron refugio en Italia no llegaron a crear unas comunidades con una lengua propia (quizá el bagitto sea lo que más se acerca a este concepto y gracias al cual se desarrolla una producción literaria, aunque muy reducida) ${ }^{49}$, pero sí una literatura híbrida, tanto en los géneros como en el idioma, debido seguramente a su identidad fronteriza, multiforme y en transformación continua.

Según Paloma Díaz-Mas, «el siglo XVII es un profundo silencio en la literatura sefardí oriental y norteafricana: no conocemos ni una sola obra ni un autor en lengua romance» ${ }^{50}$. Delante de esta ausencia, es posible suponer que la literatura producida en Italia constituya un eslabón con la comunidad de lectores y autores de las costas orientales, como ha sugerido también Laura Minervini ${ }^{51}$. El propio canovaccio del Entremés del Dotor i sus criados (1616) está ambientado en el entorno de Constantinopla y quizá un análisis lingüístico específico podría ayudar en la determinación del origen del autor: los italianismos parecerían sugerir la procedencia geográfica del anónimo dramaturgo, así como su conocimiento de los recursos de la Commedia dell'Arte podrían colocarle dentro del panorama cultural italiano, pero no se puede excluir lo contrario, es decir que el autor fuera un sefardí oriental asentado en Italia (de allí las influencias) y por esto ambientara su obra en su posible comunidad de origen, Constantinopla.

Las obras y los datos biográficos que se han comentado en las páginas anteriores demuestran la presencia difuminada de un teatro que podríamos incluir dentro del canon de la literatura sefardí. También

48 Paloma DíAz-MAs y Harm DEN BoER, «Presentación: fronteras e interculturalidad entre los sefardíes occidentales», en Fronteras e interculturalidad entre los sefardies occidentales, eds. Paloma DíAz-Mas y Harm DEN BoER (Amsterdam-New York: Rodopi, 2006) págs. 7-12: 9.

49 D’Angelo, «Scrittori giudaico-livornesi».

50 Paloma DíAz-Mas, «Pasado, presente ¿y futuro? de la literatura sefardí», Ínsula 647 (2000) págs. 3-4: 3.

${ }^{51}$ Laura MinervinI, «Experiencias culturales de los sefardíes en Italia en el siglo XVI», en Fronteras e interculturalidad entre los sefardies occidentales, eds. Paloma DíAZ-Mas y Harm den Boer (Amsterdam-New York: Rodopi, 2006) págs. 21-33: 22. 
demuestran una situación lingüística fluida, no tan definida como, en cambio, sabemos haber existido en las comunidades orientales; esto ha sido un elemento determinante a la hora de reflexionar sobre una posible definición de la identidad cultural de los sefardíes italianos.

Si todavía queda por descubrir un Fénix de los Ingenios como Lope entre los dramaturgos de origen judeo-español radicados en Italia, la que sí parece segura es la existencia de una producción teatral que, como un ave fénix, resurge de sus cenizas, logrando sobrevivir hasta nuestra contemporaneidad. Si el teatro de Bedarida ya no puede considerarse propiamente sefardí, la necesidad que el autor demuestra por rescatar los orígenes de su comunidad, es decir por recuperar las raíces judías hispano-portuguesas, indica la importancia de este pasado y de su memoria también después de 500 años de la expulsión. Una identidad, la de los sefardíes italianos, muy difuminadas, pero siempre capaz de resucitar de sus cenizas para seguir renovándose.

Recibido: 02/09/2019

Aceptado: 14/10/2019 